
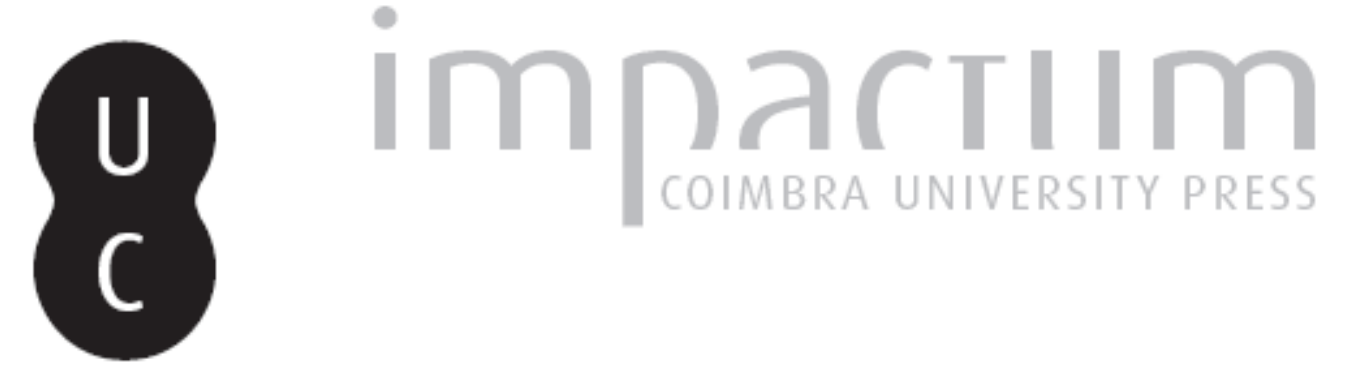

\title{
A la búsqueda de un criterior estético de la razón: la aesthetica de A. G. Baumgarten como tópica moderna de la invención
}

Autor(es): Hernández Marcos, Maximiliano

Publicado por: Imprensa da Universidade de Coimbra

URL persistente:

URI:http://hdl.handle.net/10316.2/35514

DOI:

DOI:http://dx.doi.org/10.14195/0870-4112_11_16

Accessed : $\quad$ 26-Apr-2023 07:42:04

A navegação consulta e descarregamento dos títulos inseridos nas Bibliotecas Digitais UC Digitalis, UC Pombalina e UC Impactum, pressupõem a aceitação plena e sem reservas dos Termos e Condições de Uso destas Bibliotecas Digitais, disponíveis em https://digitalis.uc.pt/pt-pt/termos.

Conforme exposto nos referidos Termos e Condições de Uso, o descarregamento de títulos de acesso restrito requer uma licença válida de autorização devendo o utilizador aceder ao(s) documento(s) a partir de um endereço de IP da instituição detentora da supramencionada licença.

Ao utilizador é apenas permitido o descarregamento para uso pessoal, pelo que o emprego do(s) título(s) descarregado(s) para outro fim, designadamente comercial, carece de autorização do respetivo autor ou editor da obra.

Na medida em que todas as obras da UC Digitalis se encontram protegidas pelo Código do Direito de Autor e Direitos Conexos e demais legislação aplicável, toda a cópia, parcial ou total, deste documento, nos casos em que é legalmente admitida, deverá conter ou fazer-se acompanhar por este aviso.

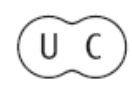




\section{ESTÉTICA E POLÍTICA}

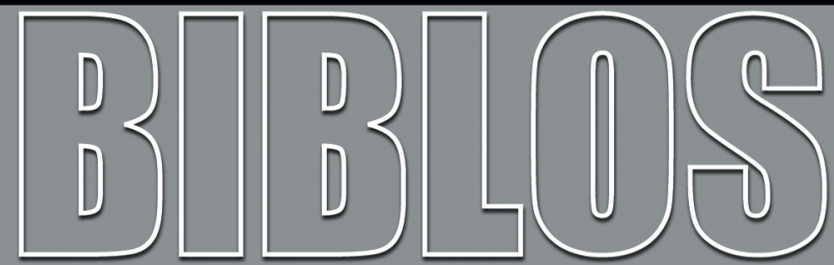

REVISTA DA FACULDADE DE LETRAS UNIVERSIDADE DE COIMBRA 
Biblos, n. s. XI (2013) 373-402

DOI: http://dx.doi.org/10.14195/0870-4112_11_16

Maximiliano Hernández Marcos

Universidad de Salamanca

\title{
A LA BÚSQUEDA DE UN CRITERIO ESTÉTICO DE LA RAZÓN. LA AESTHETICA DE A. G. BAUMGARTEN COMO TÓPICA MODERNA DE LA INVENCIÓN
}

\section{Resumen}

Este artículo se propone mostrar que la fundación de la Estética como disciplina filosófica por A.G. Baumgarten fue el primer gran proyecto de introducción de la racionalidad moderna en el ámbito del arte, y que semejante tarea se llevó a cabo mediante la elaboración de una Tópica específicamente estética, que fijaba los nuevos criterios de la invención artística. Para lograr el primer objetivo Baumgarten procedió a fundamentar filosóficamente el arte en el espacio de la sensibilidad y a concebirlo dentro de él como conocimiento "bello" o modo de representación sensible perfecta. Bajo este presupuesto la nueva ciencia de la Estética fue pensada y desarrollada sobre todo como una nueva Tópica de la invención artística que, en sustitución de la Tópica retórica tradicional, inútil para la creación de obras de arte, suministrase los nuevos criterios y reglas de racionalidad bella.

Palabras Clave: Estética, Tópica, Retórica, sensibilidad, belleza, razón, A. G. Baumgarten, perfección, Ilustración

\begin{abstract}
In this article an attempt is made to show that the founding of Aesthetics as a philosophical discipline by A. G. Baumgarten was the first great project for introducing modern rationality into the context of art, and that this task was carried out through the elaboration of a specifically aesthetic Topics that established the new criteria for artistic invention. To attain the first objective Baumgarten proceeded to provide a philosophical foundation for art in the space of sensibility and to conceive of it within this space as "fine" knowledge or the perfect mode of sense representation. Under this premise, the new science of aesthetics was considered and developed above all as a new Topics of artistic invention which, in substitution of the traditional rhetorical Topica, which was useless for the creation of works of art, would provide the new criteria and rules of "fine" rationality.
\end{abstract}

Keywords: Aesthetics, Topics, Rhetoric, Sensibility, Beauty, Reason, A. G. Baumgarten, Perfection, Enlightenment 


\section{EL MARCO GENERAL: SOBRE LA IDEA DE UNA RATIO ESTÉTICA MODERNA EN BAUMGARTEN}

En el último tercio del siglo XX se ha despertado el interés historiográfico por A. G. Baumgarten (1714-1762) y su Estética filosófica, tras los dos siglos de olvido al que el profesor de Frankfurt am Oder quedó relegado por el brillo histórico de la "revolución copernicana" de Kant y del idealismo alemán, y bajo cuya sombra no ha merecido otra consideración que la de ser visto como un pensador gris y escolar de esa Ilustración pre-crítica y racionalista que se despliega a lo largo de los años oscuros y silenciosos que van del sistema de Christian Wolff a la Crítica de la razón pura. Parece que la crisis de la Estética a finales de la pasada centuria ha podido impulsar, en su búsqueda de aire nuevo para una posible reconstitución, ese retorno fructífero de la investigación al fundador moderno de aquella disciplina ${ }^{1}$.

$\mathrm{Al}$ trasluz de esta nueva mirada, que ha tratado también de dibujar el perfil propio y autónomo del filósofo completo y de toda su obra sistemática ${ }^{2}$, la Aesthetica de Baumgarten se ha revelado, por un lado, primordialmente como una filosofía del arte que liberó a la Ilustración de un racionalismo estrecho y asfixiante mediante el reconocimiento de los derechos complementarios (gnoseológicos, metafísicos, éticos y antropológicos) de la sensibilidad, a los que da cumplimiento eminente la producción artística ${ }^{3}$ y al mismo tiempo, desde esta perspectiva, se

${ }^{1}$ Tal es la explicación de la aparición de diversas monografías y artículos sobre la Estética de Baumgarten en los años 70 del siglo XX - y de su continuación en las décadas posteriores- que ofreció Brigitte SCHEER, "Baumgartens Ästhetik und die Krise der von ihm begründeten Disziplin", Philosophische Rundschau 22 (1976), 108-119. El replanteamiento de la actualidad de la Estética de Baumgarten y de sus límites históricos fue el objetivo del número monográfico coordinado por Christoph Menke Schwerpunkt: Zur Aktualität der Ästhetik von Alexander Gottlieb Baumgarten, en: Deutsche Zeitschrift für Philosophie 46: 2 (2001), pp. 229-298.

${ }^{2}$ A esta voluntad de comprender en su peculiaridad la "filosofía" in toto de Baumgarten, como profesor de Weltweisheit, antes que su Estética en particular, responde el reciente número monográfico coordinado por Alexander Aichele, Alexander Gottlieb Baumgarten - Sinnliche Erkenntnis in der Philosophie des Rationalismus, en: Aufklärung 20 (2008).

${ }^{3}$ El estado de las interpretaciones de la Estética de Baumgarten desde los años setenta del siglo XX es, sin duda, mucho más complejo, pues tiende a situarla en una zona de tensión entre la Filosofía del arte, la Teoría del conocimiento sensible 
ha destacado, por otro lado, como un momento central en el proceso histórico de transformación o de "cambio de paradigma" del modelo topológico tradicional de concepción de la literatura y el arte al modelo creativo de la Ilustración y el Romanticismo que se inicia a finales del siglo XVII con la célebre polémica entre antiguos y modernos ${ }^{4}$. De

y la Antropología, entendida como doctrina de la nueva imagen finita del hombre basada en la rehabilitación de la sensibilidad, en la estela de la tesis de Ernst CASSIRER, Freiheit und Form. Studien zur deutschen Geistesgeschichte [1916], Darmstadt, 1975, pp.77-78. Para una visión panorámica de esta complejidad de orientaciones de la Estética, y particularmente en esta dirección ilustrado-antropológica de una cultura de la humanidad cf. Maximiliano Hernández Marcos, "Teoría de la sensibilidad, teoría de las humanidades. El proyecto filosófico de la Estética en A. G. Baumgarten”, Cuadernos dieciochistas 4 (2003), pp.81-121. No obstante, el debate central, relativo a su estatuto epistemológico, ha girado en torno a si se trata primordialmente de una Filosofía del arte y de la belleza (es la posición dominante, encabezada por Ursula FRANKe, Kunst als Erkenntnis. Die Rolle der Sinnlichkeit in der Ästhetik des Alexander Gottlieb Baumgarten, Wiesbaden, 1972) o si, lejos de restringirse al fenómeno del arte, constituye sobre todo una teoría general del conocimiento sensible y de sus diversas prácticas (es la posición defendida por Hans Rudolf SchweIzer, Ästhetik als Philosophie der sinnlichen Erkenntnis. Eine Interpretation des,,Aesthetica” A.G. Baumgartens mit teilweiser Wiedergabe des lateinischen Textes und deutscher Übersetzung, Basel, 1973). Esta ambigüedad, que se retrotrae al origen filológico del término (aisthanomai/aisthesis), tal como Baumgarten lo presenta en su Kollegium über Ästhetik [= Kollegium], \&1 (edición de Bernhard Poppe, A.G. Baumgarten: seine Bedeutung und seine Stellung in der Leibniz-Wolffischen Philosophie und seine Beziehungen zu Kant. Nebst Veröffentlichung einer Fisher unbekannten Handsschrift der Ästhetik Baumgartens, Bern/ Leipzig, 1907), es lo que Christoph Menke considera característico de la Estética filosófica contemporánea (cf. Schwerpunkt.., o.c., p.229-230). Acerca de este debate y de su estado actual v. U. Franke, "Sinnliche Erkenntnis - was sie ist und was sie soll. A.G. Baumgartens Ästhetik-Projekt zwischen Kunstphilosophie und Anthropologie », Aufklärung 20 (2008), 73-99, espec. 77-80.

${ }^{4}$ Sobre la tesis generalizada de la estetización de la retórica o cambio de paradigma de la Retórica a la Estética hacia mediados del siglo XVIII, siguiendo la línea interpretativa iniciada por Klaus DockHorn, Die Rhetorik als Quelle des vorromantischen Irrationalismus in der Literatur- und Geistesgeschichte, Göttingen, 1949, véase Eberhard Ostermann, Die Authentizität des Ästhetischen. Studien zur ästhetischen Transformation der Rhetorik, München, 2002, espec. pp.7188. Una posición más matizada y amplia, que sitúa la transformación estética de la Retórica tradicional en el marco más general del nuevo modelo o paradigma "antropológico" de la Ilustración es la de Lothar BoRnsCHEUER, "Rhetorische Paradoxien im anthropologiegeschichtlichen Paradigmenwechsel", Rhetorik 8 (1989), 13-42; y sobre todo "Die Aufklärung der Topik und die Topik der Aufklärung”, en: 
acuerdo con esta línea de interpretación, en medio de esa difícil y compleja situación de tránsito, la Estética de Baumgarten parece mirar en una dirección doble y opuesta: hacia delante, hacia la teoría románticoidealista de Schelling, F. Schlegel o incluso Hegel, que entiende el arte como conocimiento intuitivo de la verdad y exposición de lo Absoluto; y hacia atrás, hacia la tradición retórico-poética de las reglas y de los procedimientos socialmente estereotipados de la producción y formación literarias, de la que no se habría desprendido del todo, a pesar de haberla sometido a una profunda revisión y, por supuesto, a una fundamentación y sistematización filosóficas.

En el presente artículo no entraremos a discutir este estado actual de los estudios sobre Baumgarten; más bien nos servimos de ese doble horizonte - epistémico e histórico - de interpretación recién descrito como trasfondo de partida para plantear nuestro tema, dando por sentado, pues, que la Aesthetica de $1750-1758$ es prioritariamente una reflexión filosófica sobre el arte y que con ella Baumgarten contribuye decisivamente a la modificación de la visión heredada, humanísticobarroca, de la actividad artística y literaria, y al surgimiento de la nueva concepción pre-romántica e ilustrada. Nuestra (hipó)tesis hermenéutica a este respecto, de la que queremos ofrecer aquí un argumento relevante, dice que podemos leer el proyecto intelectual del profesor de Frankfurt am Oder como el primer gran intento dentro de la cultura europea de definir una ratio estética moderna. Con ello quiere indicarse que Baumgarten trató de introducir en el ámbito sociocultural, entonces difuso e indeterminado, de las así llamadas artes liberales y bellas aquella nueva racionalidad metódica de origen matemático que se había inaugurado a comienzos del siglo XVII con la ciencia natural (ratio científica) y que durante la segunda mitad de ese siglo se había proyectado con éxito sobre el campo de la acción sociopolítica mediante la construcción de los grandes sistemas del Derecho Natural (ratio moral).

Siegfried JütTner/Jochen Schlobach (Hg.), Europäische Aufklärung(en): Einheit und nationale Vielfalt, Hamburg, 1922, pp. 54-65. Christoph Menke, sin embargo, prefiere hablar, en el caso de Baumgarten, de "reescritura" de la tradición retóricopoética, en vez de "sustitución" estética, y más que ver en él una posición "intermedia" entre el racionalismo del siglo XVII y el idealismo iniciado por Kant, lo considera representante de una "corriente subterránea" o paralela a la de la teoría moderna de la subjetividad (cf. Schwerpunkt..., pp. 230-231). 
Puesto que semejante ratio moderna implicaba la sustitución del viejo modo de pensar (y saber) topológico, con su flexibilidad y ubicuidad argumentativa, por la nueva manera metódico-conceptual de delimitación de los espacios y objetos de la realidad y de circunscripción exacta de nuestro conocimiento, su aplicación histórica se tradujo en un trabajo cultural de doble dirección: una sistematización unitaria del saber, que suministrara un mapa global y coherente del mundo, y a la vez una construcción diferenciada de los diversos territorios o esferas de la realidad, que captase conceptualmente su específico funcionamiento. La ratio moderna significaba, por tanto, desde el punto de vista metodológico, una reorganización sistemático-conceptual precisa de los espacios del mundo y, desde el punto de vista ontológico, la identificación de un ordo o regularidad específico de cada espacio y compatible con el de los demás. A la filosofía correspondía obviamente esta ambiciosa tarea de confeccionar el nuevo mapa ordenado de la racionalidad moderna.

Si ahora volvemos los ojos hacia el proyecto intelectual de la Estética de Baumgarten y a su ejecución, advertimos claramente este doble propósito de fundación racional. En él alienta, en primer lugar, una voluntad firme y consciente de definición y sistematización filosóficoconceptual como espacio unitario de un amplio campo de saberes, prácticas culturales y experiencias sociales nuevas (artes bellas, studia humanitatis, fenómenos recientes del gusto y de la crítica...) que en su diversidad carecían de una delimitación precisa y clara y, sobre todo, no habían sido aún sometidos al trabajo analítico de esclarecimiento y distinción conceptuales que exigía la nueva ratio moderna, porque en buena medida parecían, de entrada, resistirse a su disección metódica y se presentaban por ello como algo "irracional"s. No en balde Dominique Bouhours había declarado la imposibilidad de reducir a ideas claras y distintas lo peculiar de cualquier obra o producto del ingenio creativo mediante su célebre "je ne sais quoi", un dictamen que el propio Leibniz hacía suyo al referirse a esa extraña confusa cognitio en que, según

${ }^{5}$ Este reto de someter a la razón lo que se presentaba como irracional es el planteamiento y el tema del libro clásico de Alfred BAEUMLER, Das Irrationalitätsproblem in der Ästhetik des 18.Jahrhunderts bis zur critik der Urteilskraft [1923], Darmstadt, 1967, espec. pp.4-5. 
él, se basaba la experiencia y juicio de una obra de arte ${ }^{6}$. Baumgarten, al proponer la Estética como nueva disciplina filosófica, asumía precisamente el reto de delimitar con precisión y nitidez un nuevo territorio de la vida humana mediante la unificación de su variada praxis bajo nociones y principios generales. Proporcionar esos "principios adecuados" y comunes a todos los studia humanitatis y a las "artes liberales", de tal forma que bajo este conocimiento de su base común cada arte pudiera luego cultivarse específicamente mejor $^{7}$, constituye precisamente una de las principales ventajas de la nueva ciencia filosófica, a

${ }^{6} \mathrm{Cf}$. Dominique Bounours, La manière de bien penser dans les ouvrages d'esprit. Dialogues, Ámsterdam, 1688 ; Gottfried Wilhelm LeIBnIZ, Meditationes de cognitione, veritate et ideis [1684], en: C. J. GERHARDT (Hg.), Die philosophischen Schriften von Gottfried Wilhelm Leibniz, Hildesheim/New York, 1978, vol. 4, p.423; Discurso de metafísica [1686], Madrid, 1981, \&24, p.87; y Nuevos ensayos sobre el entendimiento humano [publicado en 1765], Madrid, 1983, p.47.

${ }^{7}$ Alexander Gottlieb Baumgarten, Aesthetica - ̈̈sthetik, 2 Teile, hrsg. Dagmar Mirbach, Hamburg, 2007, \&3 y \&5 [=Aesthetica]. Cf. Georg Friedrich MeIER, Anfangsgründe aller schönen Wissenschaften, Halle, 1748, 1. Theil, \&16 [= Anfangsgründe] (la Estética "contiene todos los fundamentos de las artes libres y de las ciencias bellas") y "Einleitung", pp.1-2; y Betrachtungen über den ersten Grundsatz aller schönen Künste und Wissenschaften, Halle, 1757, \&\&7 y ss., donde en respuesta a las objeciones planteadas contra la posibilidad, necesidad y utilidad de la Estética Meier se pronuncia abiertamente sobre las ventajas de la sistematización racional bajo un principio supremo que ella lleva invocando la imagen geométrica del centro del círculo. "La verdadera utilidad" -escribe- "que cabe esperar del descubrimiento de un principio general del que fluyan todas las artes y ciencias bellas, es cuádruple. La primera es que de este modo se favorece el orden y lo sistemático en el conocimiento de las reglas de las artes y ciencias bellas. Un verdadero sistema o edificio bien trabado y coordinado puede surgir únicamente si todas las ideas que lo constituyen en su conjunto se derivan de una única fuente. Pues entonces todas ellas van a parar a esa única fuente, igual que los radios de un círculo confluyen en el centro. [...]". La segunda utilidad consiste en que de esta manera "se obtiene un concepto general según el cual hay que pensar y actuar cuando se practiquen esas artes y ciencias, y conforme al cual hay que juzgar si cualquiera de sus reglas es verdadera o falsa [...]". La tercera ventaja es que gracias a ello "se aprende a comprender la íntima afinidad [Uebereinstimmung] de todas esas artes y ciencias [...]" (en: G. F. MEIER, Frühe Schriften zur ästhetischen Erziehung der Deutschen, Teil 3, Halle/Saale, 2002, pp.175-178).

Nota del autor: A lo largo de este artículo se citarán las obras de Baumgarten y Meier de forma abreviada, según las iniciales de la edición que aparecen entre corchetes la primera vez que se hace referencia a la obra. Las traducciones del latín o del alemán son todas mías. 
la cual Baumgarten califica de "Estética artificial" justamente en virtud de su estatuto teórico-epistémico de conocimiento racional, claro y distinto sobre la práctica habitual del juicio y la producción artísticas, basada en el desarrollo de determinadas capacidades creadoras, que él denomina "estética natural".

Es claro, sin embargo, que esta delimitación y ordenación racional del espacio del arte y la literatura no podía llevarse a cabo sin la debida inserción en el marco general de un sistema global, desde el que pudiera garantizarse su coordinación con los demás espacios racionalizados y perfilarse así nítidamente su diferencia específica. Para alcanzar este propósito Baumgarten procede a poner en contacto las dos tradiciones culturales en las que él se había formado, pero que se hallaban históricamente separadas entre sí: la tradición retórico-poética de origen humanista y la nueva filosofía racionalista de Leibniz y Wolff. Como consecuencia de este entrelazamiento ninguna de las dos podía quedar ya inalterada. Así, la Retórica y la Poética no sólo recibían ahora ese tratamiento filosófico que Baumgarten echaba en falta en su escrito inaugural Meditationes philosophicae de nonnullis ad poema pertinentibus (1735) ${ }^{9}$; los principios y conclusiones de la fundamentación filosófica de la producción literaria, en la medida en que suponían la identificación racional de un espacio nuevo, del que formaban parte otras artes y saberes, debían valer también para estas últimas, de manera que aquella filosofía poética inicial tenía que ampliar su alcance epistémico y transformarse en esa filosofía del arte en general que se elabora en la inconclusa Aesthetica de 1750-58. Por su parte, la filosofía de Leibniz y Wolff, si quería definir y dar cuenta racionalmente del nuevo espacio estético, tenía que abrir igualmente su estructura sistemática para dar cabida a una nueva "filosofía instrumental" que definiese epistémicamente la índole propia de la experiencia y expresión artísticas; a la

${ }^{8}$ Sobre la distinción entre "Estética artificial" y "Estética natural" v. A.G. Baumgarten, Aesthetica,, \&\&2-3; y G. F. MeIer, Anfangsgründe, \&12. Sobre la Estética filosófica como conocimiento "distinto" o analítico-racional v. A.G. Baumgarten, Aesthetica, \&8.

${ }^{9}$ Cf. Prólogo de A. G. Baumgarten, Meditationes philosophicae de nonnullis ad poema pertinentibus - Philosophische Betrachtungen über einige Bedingungen des Gedichtes, hrsg. Heinz Paetzold, Hamburg, 1983, pp.3-4 [= Meditationes], donde da cuenta de su plan juvenil de aplicar la filosofía aprendida a la definición del poema. 
Lógica como doctrina de la razón debía añadirse, por tanto, la Estética como gnoseología inferior o doctrina de la sensibilidad. Pues lo que Baumgarten había descubierto era que aquella resistencia a la claridad analítico-intelectual de la experiencia del gusto y de las obras de arte se debía a que arraigaban en un ámbito distinto al de la mera razón, el ámbito de la así llamada "facultad inferior de conocer" o sensibilidad humana, cuya identificación teórico-conceptual permitía ahora su estudio filosófico y el consiguiente esclarecimiento de su lógica o racionalidad específica.

La detección de una racionalidad propia del ámbito de la sensibilidad y su análisis conceptual era, por otra parte, una tarea imprescindible para la constitución de una ratio estética moderna. El trabajo metodológico de delimitación y ubicación del nuevo espacio de lo sensible dentro del sistema filosófico de la razón sólo tenía sentido si era posible, en segundo lugar, hallar y definir con precisión un orden específico y particular del nuevo ámbito, que pudiera traducirse cognoscitivamente en un conjunto de conceptos y principios generales, de los que cupiera extraer reglas útiles para refinar el gusto y mejorar la creación artística. Baumgarten y su discípulo Meier siempre vincularon esta utilidad educativa y práctica de la Estética a su condición de ciencia filosófica, encargada de exponer y enseñar los "primeros fundamentos" y reglas "del conocimiento bello y de todas las ciencias bellas"10. Y basaron a su vez esta identificación de principios y reglas en la admisión de un orden en y de la sensibilidad, que para ellos era además la manifestación de un orden metafísico y real (no meramente subjetivo) del mundo. Esta convicción metafísica, que determina también el valor cognoscitivo del arte, sale a relucir con toda franqueza en las primeras páginas de los Anfangsgründe aller schönen Wissenschaften de G. F. Meier. Allí se declara abiertamente que "en el mundo domina un orden tan general y excelente" que todo sucede según regla, y que esta perfección se despliega o realiza en el ámbito sensible en forma de "belleza" ${ }^{11}$. La

${ }^{10}$ G.F. MeIER, Anfangsgründe, 1. Theil, Einleitung, \&1, p. 2; A.G. BAUMGaRTEN, Aesthetica, \&3.

${ }^{11}$ G. F. MeIER, Ibid., \&1, pp. 1-2. Salvatore Tedesco, L'estetica di Baumgarten, Palermo, 2000 ha sostenido con acierto que la Estética de Baumgarten se propone investigar la racionalidad de lo sensible, la cual radica en las "conexiones plurales propias de la sensibilidad" (p.88), dado que, según su Ontología, el con- 
antigua suposición de un cosmos mundano, rehabilitada y reformulada por Leibniz mediante la idea de la perfección del mundo creado, constituye, por tanto, la base metafísica de la racionalidad de lo sensible, ligada de este modo a la belleza, así como el límite de la comprensión de la experiencia y creación artísticas como percepción y producción de orden bello, jamás - a diferencia del Romanticismo - como sensación y provocación del caos. Ya en su primer escrito, al referirse al orden del poema, Baumgarten señalaba que debe ser de algún modo reflejo o expresión del orden mundano, pues "lo que para los filósofos resulta evidente acerca del mundo real se ha de mantener, por analogía, acerca del poema" ${ }^{12}$. En esta capacidad de identificar o crear un orden similar al del mundo real en la obra de arte se fundamenta la calificación de la sensibilidad como analogon rationis, esto es, como una facultad que puede captar y generar a nivel intuitivo el mismo nexo de las cosas que la razón aprehende conceptual y analíticamente ${ }^{13}$.

nexum (el nexo posible y adecuado) es rationale (A.G. BAUMgarten, Metaphysica, \&19, p.30, en: Baumgartens Metaphysica, en: Kant's gesammelte Schriften, hrsg. Preussische Akademie der Wissenschaften, Berlin/Leipzig, 1926, Bd. XVII $[=$ Metaphysica $]$ ).

${ }^{12}$ A. G. Baumgarten, Meditationes, \&68. Sobre el orden interno de una obra en general como representación del orden externo de las cosas v. Aesthetica, \&\&19-20. "Las obras de arte" - ha escrito al respecto U. Franke - "ofrecen una perspectiva análoga al cosmos y en oposición al caos. Son signos del universo. Este trasfondo metafísico lleva consigo no en balde una condena del absurdo" (Ursula Franke, "Mit der Metaphysik im Rücken. Zu Baumgartens > significatio aesthetica < und Wolffs > significatus hieroglyphicus<", en: Christian Wolff und die europäische Aufklärung. Akten des 1.Internationalen Christian-Wolff-Kongresses, Halle (Saale), 4.-8.April 2004, hrsg., Jürgen Stolzenberg und OlivierPierre Rudolph, Hildesheim u. a., 2008, 4. Teil, p.237 [en: Gesammelte Werke, 3.Abteilung: Materialien und Dokumente, Bd. 104: Wolffiana II.4]). Cf., Kunst als Erkenntnis..., o.c., p. 102 ss.

${ }^{13}$ Baumgarten introduce por primera vez el concepto de analogon rationis en el capítulo de "Psicología empírica" de su Metaphysica (1739), \&640 con estas palabras: "Todas éstas [las facultades inferiores de conocer], en cuanto que son similares a la razón en el nexo que representa las cosas, constituyen el análogo de la razón, es decir, el conjunto de las facultades del alma que representan confusamente ese nexo" (Baumgartens Metaphysica, en: Kant's gesammelte Schriften, hrsg. Preussische Akademie der Wissenschaften, Berlin/Leipzig, 1923, Bd. XV.1, p.39. El término procedía de la Psicología animal y había sido empleado por Leibniz (Monadologie, \&26; Principes de la nature et de la grâce, \&5) y Ch. Wolff (Vernünffige Gedancken von Gott, der Welt und der Seele des Menschen, \&\&374 
Una vez expuesto a grandes rasgos el plan de Baumgarten y Meier de definir una ratio estética en el campo del arte conforme al método científico-conceptual moderno y su convicción de orden y regularidad en el mundo, nos proponemos a continuación presentar el nuevo criterio de racionalidad estética que ambos autores plantearon a su época, y que si bien mantiene todavía la vieja idea normativa de belleza, supone ya una ruptura con la tradición retórico-poética, puesto que se fundamenta ahora en unos presupuestos ontológicos y psicológicos enteramente nuevos, entresacados de la filosofía de Leibniz y Wolff. La caracterización de ese criterio estético ha de resultar de la respuesta a las dos preguntas siguientes:

1) ¿Cuál es o en qué consiste el orden del mundo que la sensibilidad representa y conoce? Abordar esta cuestión requiere un análisis de la noción de belleza (pulcritudo) como perfección sensible (perfectio cognitionis sensitivae, perfectio phaenomenon).

2) ¿Cómo se consigue semejante orden y perfección en la representación sensible, artística del mundo?; ¿cuáles son las reglas y procedimientos para la creación de una obra genuinamente artística o las notas y rasgos que debe reunir para ser percibida y juzgada como bella? La respuesta a esta cuestión pasa en Baumgarten por una discusión crítica con la Tópica tradicional, incapaz de ejercer la función de ars inveniendi en el campo de las bellas artes, así como por la propuesta alternativa de una nueva Tópica estética, que se construye desde una doble perspectiva: la ontológico-objetiva de las perfecciones de las cosas y de su conocimiento sensible (categorías estéticas o criterios de la pulcritudo materiae, rerum et cogitationum) y la psicológico-subjetiva de las facultades inferiores del alma que debe reunir un

ff.) para referirse a la "expectativa de casos similares" basada en la memoria o la imaginación. Baumgarten, sin embargo, amplía este concepto y lo convierte en una noción psico-gnoseológica que designa la capacidad de un orden en la representación sensible del alma humana la sensibilidad. Sobre este concepto v. U. FRANKE, “Analogon rationis", en: Historisches Wörterbuch der Philosophie, hrsg. J. Ritter, 1971; y Stefanie Buchenau, "Sinnlichkeit als Erkenntnisvermögen. Zum Begriff des Vernunftähnlichen in der Psichologie Christian Wolffs", en: Oliver-Pierre RudolPh/Jean-François Goubet (Hg.), Die Psychologie Christian Wolfs. Systematische und historische Untersuchungen, Tübingen, 2004, 191-206. 
artista creador, un "carácter de esteta" (character aesthetici) o espíritu bello (criterios de la pulcritudo ingenii et personae). La importancia de este asunto la pone de manifiesto el hecho de que el capítulo primero y principal de la Estética teórica de Baumgarten -y el único, aunque inacabado, que llegó a redactar- está dedicado a esta nueva heuristica, y todas sus secciones, salvo la introductoria sobre la belleza en general, se ocupan sucesiva y pormenorizadamente de los nuevos topoi. Es evidente que al estructurar su Aesthetica de 1750-58 en torno a estos criterios de invención artística Baumgarten era plenamente consciente $-\mathrm{y}$ tal era su propósito- de estar definiendo una racionalidad estética en relación con el gusto y el arte.

\section{EL CONCEPTO PRINCIPAL: LA BELLEZA COMO PERFECCIÓN SENSIBLE}

Baumgarten y Meier mantienen, conforme a la tradición, la idea de la belleza como objeto del arte y criterio distintivo de lo artístico, pero la conciben, siguiendo a Leibniz, como un tipo de perfección que no es, sin embargo, inherente al ente en cuanto tal (no forma parte de sus predicados ontológico-trascendentales) sino a su modo de realización y representación sensible por parte del hombre. Estamos, sin duda, ante una concepción compleja y novedosa, que se sitúa en un difícil equilibrio entre la antigua doctrina platónico-intelectual de la objetividad ontológica de lo bello en sí y la nueva visión ilustrada de su índole esencialmente subjetiva. Pues como "especie" del género "perfección"14, que es uno de los tres trascendentales del ser (unum, verum, perfectum), la belleza tiene en Baumgarten una dimensión metafísico-objetiva que la relaciona con la realidad misma del mundo en cuanto cosmos, y hace de la experiencia estética en general y, sobre todo, del arte en particular una forma de conocimiento válido, de acceso genuino a la verdad de las cosas. Mas como representación o modo de ser sensible de una perfección (phaenomenon), la belleza deja de constituir un asunto propio del entendimiento - como aún en Leibniz - y, por supuesto, una idea pla-

${ }^{14}$ G. F. MEIER, Anfangsgründe, \&3, p.6. 
tónica, para convertirse en un elemento distintivo de la finitud humana y en fundamento valorativo de la pluralidad y complejidad empíricas del mundo ${ }^{15}$. De ahí que Baumgarten y Meier, anticipándose a Schiller, hayan vinculado la educación estética de la sensibilidad al ideal de una humanidad civilizada, frente a la barbarie de una cultura meramente escolar y erudita del entendimiento, y hayan calificado por ello las artes liberales y bellas de mansuetiores et humaniores ${ }^{16}$.

La concepción de la belleza presupone, pues, en Baumgarten, desde el punto de vista histórico, una rehabilitación gnoseológica, metafísica e incluso ética de la sensibilidad frente a su devaluación en el marco del racionalismo alemán y de la religiosidad pietista dominante en Halle. De esa rehabilitación forma parte -es su núcleo central- el reconocimiento de lo sensible como un ámbito de perfecciones y, por consiguiente, también de un orden y racionalidad específicos, así como de la capacidad humana de captarlas y sobre todo representarlas cognoscitivamente mediante el arte. Veamos brevemente los dos pasos de esta operación intelectual.

\section{Rehabilitación gnoseológica y metafísica de la sensibilidad}

En su primer escrito de 1735, las Meditationes philosophicae de nonnullis ad poema pertinentibus, Baumgarten inicia una rehabilitación esencialmente gnoseológica de la sensibilidad, que completa en el capítulo sobre la "Psicología empírica" de su Metaphysica (1739), donde le otorga además -como veremos- la acreditación metafísica de

${ }^{15}$ No es casual que Baumgarten y sobre todo Meier hablen de "bellezas" y "perfecciones", en plural, puesto que la pluralidad, dentro de un orden, obviamente, es lo que caracteriza a nuestro mundo real como el mejor de los mundos posibles, según Leibniz. El carácter humano-sensible de la belleza no impide a Baumgarten reconocer una pulcritudo intellectualis (A.G. BAumgarten, Metaphysica, \&637), ciertamente intuitiva, y que correspondería en todo caso al entendimiento divino. Sobre esta "belleza intelectual" no hay, sin embargo, en la obra de Baumgarten más que la mera definición del citado \&637 de su Metaphysica.

${ }^{16}$ G. F. MeIER, Anfangsgründe, \&15, p.26 (sobre la crítica a la mera erudición y enseñanza escolar como barbarie, espec. \&\&14-16). Cf. A. G. BAUMGARTEN, Aesthetica, \&\&3 y 6; y Kollegium, \&\&3 y 6. Cf. E. CASSIRER, Freiheit und Form..., p.78. 
ser la forma de conocimiento de lo singular, que constituye la auténtica realidad del mundo. Para llevar a cabo aquella validación cognoscitiva -obviamente, desde la perspectiva de la nueva ciencia psicológica instituida por Wolff- Baumgarten no sólo transforma la mera gradación leibnizo-wolffiana de partes (superior/inferior) de la facultad de conocer en dos facultades autónomas, que se ocupan respectivamente del conocimiento "distinto" (facultas cognoscitiva superior) y del conocimiento "confuso y oscuro" (facultas cognoscitiva inferior), sino que también identifica esta última con la sensibilidad, trasladando y extendiendo de este modo una noción procedente de la doctrina de la facultad apetitiva a la doctrina de la facultad de conocer $^{17}$. El espacio propio del conocimiento sensible, abierto psicológicamente en el alma humana por la nueva facultad cognoscitiva inferior, queda así delimitado como el ámbito de las representaciones oscuras y confusas, es decir, las "no distintas", a las que ni Leibniz ni Wolff, a pesar de haberlas admitido, no les habían concedido un estatuto gnoseológico autónomo.

Ahora bien, la admisión de un ámbito psico-gnoseológico propio de la sensibilidad no lleva consigo de por sí su acreditación epistémica como un territorio de conocimiento válido, que nos dé noticia mínimamente determinada y verdadera del mundo, de sus objetos y, sobre todo, de su orden y relaciones empíricas. La validación epistémica de la facultad inferior de conocer y del territorio de lo sensible depende, pues,

${ }^{17}$ En Ch. Wolff lo "sensible" se predicaba exclusivamente de aquel apetito que procedía de una "idea confusa de lo bueno" (cf. Ch. WolfF, Psychologia empirica, \&580, en: Gesammelte Werke, hrsg. J. École et al., II. Abteilung, Lateinische Schriften, Bd. 5, Hildesheim, 1968). Baumgarten en sus Meditationes de 1735 exige ya, sin embargo, que se predique igualmente de las representaciones mismas que sean "confusas y oscuras", y de la facultad cognoscitiva que se ocupa de ellas (Meditationes, \&3). En aquel escrito poetológico no hay, empero, una posición clara acerca del estatuto psicológico de la sensibilidad, pues Baumgarten oscila entre considerarla meramente la "parte inferior" de la facultad cognoscitiva (Meditationes, \&3) y concederle ya la autonomía propia de una "facultad inferior de conocer" (Ibíd.., \&115). Es en la Metaphysica (1739), \&520 donde la sensibilidad queda definitivamente reconocida como facultas cognoscitiva inferior del alma humana y, por tanto, como el ámbito específicamente diferenciado de las representaciones no distintas [non distinctae, undeutliche], o sea, no intelectuales. "Se llama sensible a la representación no distinta. Por consiguiente, la fuerza de mi alma hace presente [repraesentat] percepciones sensibles a través de la facultad cognoscitiva inferior" (A. G. BAUMGarten, Metaphysica, \&521, p.9). 
de que nos suministre representaciones con un mínimo de claridad tal que sea posible siquiera identificar inmediatamente un objeto frente a otro, aun cuando no sea mediante un discernimiento analítico-reflexivo, preciso y diferenciado, de sus notas constitutivas ${ }^{18}$. Dado que no hay conocimiento sin una mínima claridad, el rendimiento cognoscitivo de la sensibilidad sólo puede radicar en las representaciones confusas, por más que en ellas perviva siempre un resto inextirpable de oscuridad. Leibniz les había ya reconocido esa claridad suficiente para identificar la cosa representada a través de y a pesar de la indistinción perceptiva de sus diversas notas ${ }^{19}$, pero no había entrado a examinar (tampoco lo hará Wolff) con más detalle en qué consiste esa claridad de la confusa cognitio y menos aún se había planteado la posibilidad de vislumbrar ahí algún tipo de perfección. Ésta es precisamente la gran novedad introducida por Baumgarten ya en sus Meditationes de 1735, al definir allí el poema como "discurso sensible perfecto" y vincular lo "poético" -lo artístico en general- a esa perfección del conocimiento sensible ${ }^{20}$. La rehabilitación gnoseológica de la sensibilidad se consumaba de este modo gracias a su fundamentación metafísica no sólo psicológicamente en el alma humana como sustancia monádica que cuenta con una facultad inferior de conocer el mundo mediante representaciones clarae et confusae, sino también gracias a su acreditación ontológica como un ámbito propio de perfecciones, que conciernen a la representación sensible (no intelectual) de las cosas.

Pero ¿dónde podía estar la perfección de lo sensible?; ¿en qué podía consistir? Obviamente no podía residir en el carácter cognitivamente confuso de las representaciones sensibles, ya que su falta de claridad

18 "Cognitio vera est realitas" -escribe Baumgarten en su Metaphysica, \&515. Conocimiento válido o verdadero es el que dice algo positivo de la realidad del mundo, pero decir algo equivale a identificar al menos un objeto por medio de notas o predicados (determinationes) discerniéndolo de otro (cf. Metaphysica, \&36). Baumgarten empieza por ello la primera sección del capítulo sobre la Psicología empírica de su Metaphysica diferenciando, muy platónicamente, dentro del espacio representativo infinito del alma humana entre un "campo de oscuridad" o "reino de las tinieblas" y un "campo de claridad" o "reino de la luz" (Metaphysica, $\& \& 514,518)$

${ }^{19}$ G.F. LeIBNIZ, Meditationes de cognitione..., o.c., pp.422-423; cf. Discurso de metafísica, \&24.

${ }^{20}$ A. G. Baumgarten, Meditationes, o.c., \&\&9 y 11. 
lógica plena es una imperfección constitutiva; precisamente por esto la sensibilidad se entiende como una facultad "inferior" con respecto a la razón, cuya superioridad reside en esa perfección lógica de su conocimiento nítido o distinto. Lo perfecto del conocimiento sensible tenía que estar en otro aspecto, cuyo desarrollo competía al arte: en la complejidad o plenitud de sus notas, una complejidad, sin embargo, armónica, a la que Baumgarten llama "belleza" ${ }^{21}$. En esto la sensibilidad es superior al entendimiento; su falta de claridad conceptual (confusión) se revela como ganancia de claridad compleja, la cual representa mejor que la nitidez abstracta y universal de la razón, la realidad metafísica del mundo, constituido por individuos monádicos, plenos de determinaciones. En las Meditationes Baumgarten destacaba ya esta superioridad cognoscitiva de la poesía -y del arte en general- como "representación singular" de los individuos del mundo ${ }^{22}$. Pero pasemos a ver con más detalle qué es y qué implica esta perfección sensible que define a la belleza.

${ }^{21}$ En respuesta a una objeción sobre la presunta dignificación de la "confusión" lógico-cognoscitiva, que es la "madre del error", Baumgarten responde que él no hace de ella el objetivo de su Estética, ni "la recomienda" (Aesthetica, \&7). Y en la Lección aclara que él no busca el conocimiento confuso "porque sea confuso, sino porque es vivaz [lebhaft]" (Kollegium, \&7, p.77). En esta misma línea señala que no pone "la belleza en la confusión" como tal sino en el modo como se enlazan "las representaciones confusas" (Kollegium, \&17, p.81). Sobre este punto v. U. Franke, Kunst als Erkenntnis..., p.81, quien recuerda a este respecto que para Baumgarten no toda representación sensible es una representación bella o perfecta; la belleza tiene que ver con una determinada forma de conexión de representaciones confusas. Sobre la noción de "complejidad" o "plenitud de notas", a la que volveremos más adelante, v. U. FranKe, o.c., pp.48-49.

22 "Los individuos están absolutamente determinados. Por consiguiente, las representaciones singulares son especialmente poéticas" (A. G. BAUMGARTEN, Meditationes, \&19). A diferencia de los entes "singulares" o individuos, el "ente universal" está menos determinado, contiene menos notas (Metaphysica, \&148). Ahora bien, el mundo real está constituido sustancialmente de mónadas (cf. Metaphysica, \&234), que son entes individuales o singulares, de manera que sólo "el arte puede aspirar a conocer en su individualidad a los individuos de los que se compone la realidad metafísica" (Pietro PimPinella, "Veritas aesthetica. Erkenntnis des Individuellen und mögliche Welten”, Aufklärung 20 (2008), p.47). 


\section{Belleza como perfectio phaenomenon: noción heurística y noción metafísica}

La noción de belleza en Baumgarten sigue siendo un asunto enigmático y debatido entre los especialistas. Albert Riemann planteó el problema como una ambivalencia -o tal vez un giro evolutivo- entre la noción "racional-objetiva" de la Metaphysica, \&662, y la noción "racional-subjetiva" de la Aesthetica, \&14. Veamos ambas definiciones:

"La perfección fenoménica [perfectio phaenomenon] o perceptible por el gusto en sentido amplio [seu gustui latius dicto observabilis] es la belleza".

"El fin de la Estética es la perfección del conocimiento sensible como tal. Pero esto es la belleza, Metaphysic. \&\&521, 662"23.

Según Riemann, en la primera definición la belleza es la "perfección absoluta", "metafísica" del mundo representada como un "fenómeno" del alma humana, mientras que en la segunda resulta dinámicamente de una "función especial" de nuestra "actividad representativa", en virtud de la cual la perfección de lo bello se convierte propiamente en una tarea de la subjetividad sensible. La diferencia estaría, en suma, entre la idea de una "perfección que aparece" y la de una "perfección de las apariencias" o "fenómenos" 24 .

La ambivalencia que Riemann presenta como problema, se despeja fácilmente si se la contempla desde la perspectiva adecuada. Es indudable que el propio Baumgarten ha sido muy lacónico en la caracterización de un concepto tan relevante. Pues, en rigor, de la belleza como tal sólo nos ha dejado la definición del \&662 de la Metaphysica, a la cual se remite en la Aesthetica, \&14 como a algo ya consabido. Este desinterés teórico por el concepto mismo de lo bello indica que era algo obvio para él, y que el verdadero centro de atención de su reflexión estética estaba en otra parte: en el esclarecimiento y descripción del modo de construcción o producción artística de la belleza, de esa forma creativa de

${ }^{23}$ Respectivamente Metaphysica, \&662, p.45; y Aesthetica, \&14, p.20.

${ }^{24}$ Albert Riemann, Die Aesthetik Alexander Gottlieb Baumgartens unter besonderer Berücksichtigung der Meditationes de Nonnullis ad Poema Pertinentibus nebst einer Übersetzung dieser Schrift, Halle, 1928, 37-38. 
operar que él llama "pensar bello" (pulcre cogitare). La sección sobre la pulcritudo cognitionis con la que se inicia no en vano el capítulo de la "heurística" -el principal, aunque inacabado, de la Aesthetica-, está dedicada precisamente a trazar las líneas generales, el esqueleto básico de ese arte de la invención de lo bello, que irá desarrollando en las secciones siguientes. Por eso en vez de una definición exhaustiva del concepto de belleza, que allí se da por supuesto mediante la referencia al \&662 de la Metaphysica, se nos presenta la meta de la Estética ("Aesthetices finis") como ciencia, a saber, la tarea de mostrarnos cómo perfeccionar nuestro conocimiento sensible y lograr que sea "bello", la de describirnos, en definitiva, el "procedimiento cognoscitivo" de creación artística de belleza ${ }^{25}$. Desde esta perspectiva se entiende mejor lo que Riemann interpreta como concepto "racional-subjetivo". En realidad, no hay tal concepto; eso que él denomina noción subjetivo-funcional de belleza no es más que la definición operativa de cómo crear una obra de arte bella, cómo convertir artísticamente representaciones sensibles en "conocimiento bello". Desde este punto de vista heurístico, en cuanto realización cognoscitiva del sujeto creador, se comprende que la belleza se caracterice como perfectio cognitionis sensitivae, pero en el sentido preciso del perfeccionamiento del conocimiento sensible que la actividad artística lleva consigo ${ }^{26}$.

La cuestión está ahora en saber si esta noción heurística de belleza referida al arte, en la medida en que constituye una construcción sensible del sujeto, tiene un alcance meramente subjetivo, o si, por el contrario, guarda alguna relación con el mundo real y, en este aspecto, cuenta también con un significado objetivo. Aquí es donde entra en juego el otro concepto mencionado por Riemann: la noción metafísica de belleza. Pues para Baumgarten la belleza del arte no consiste simplemente en una recreación veleidosa y autista de la fantasía ilimitada del sujeto, desconectada de la realidad cósmica y de su belleza natural. El perfec-

${ }^{25}$ Salvatore Tedesco, L'estetica di Baumgarten, p.75. Comparto por completo la interpretación de Tedesco en este tema. No es muy distinta al respecto la de Ursula Franke, Kunst als Erkenntnis..., 77 ss., 88-89.

${ }^{26}$ Cf. S. Tedesco, L'estetica di Baumgarten, p.14, 75. Con razón se ha llegado a traducir el término "perfectio" de la expresión perfectio cognitionis sensitivae de la Aesthetica, \&14, como perfeccionamiento ("Vervollkommnung") (así H. R. Schweizer en su edición selecta A. G. Baumgarten, Theoretische Ästhetik, Hamburg, 1988, p.11). 
cionamiento que el artista lleva a cabo en el conocimiento sensible, lo que él conoce y presenta intuitivamente en su obra bella, constituye, en realidad, una variación actualizadora de la perfección sensible del mundo, una acción representativa que da a conocer y a la vez enriquece (mediante esa perfección sensible que es cada obra de arte) el orden perfecto en el que vivimos. El concepto heurístico de belleza del arte presupone, por tanto, el concepto metafísico de belleza natural en el que se funda, y la función cognoscitiva que Baumgarten atribuye a las creaciones artísticas se basa precisamente en que "lo metafísicamente perfecto" se hace presente en "la representación estética de lo bello en las artes" 27 . Esta fundamentación filosófica de la belleza heurística en la belleza metafísica es lo que lleva a cabo el \&14 de la Aesthetica mediante la invocación del \&662 de la Metaphysica. Gracias a esa fundamentación la belleza de la obra de arte como construcción subjetiva es, al mismo tiempo, objetiva, es decir, constituye un objeto sensible perfecto, una perfección fenoménica.

Pero ¿qué es la perfectio phaenomenon, qué significa? Este concepto metafísico carga a la belleza -se ha dicho atinadamente- con una ambivalencia objetivo-subjetiva ${ }^{28}$, pues mediante él se alude a una perfección de las cosas (sean objetos naturales u obras de arte) que es y existe únicamente como fenómeno, como objeto perceptible de nuestra sensibilidad. La dimensión subjetiva de la belleza reside ciertamente en esta índole estrictamente fenoménica. Mas con ello no se indica que lo bello consista meramente en el modo sensible e intuitivo de acceder el sujeto humano a una perfección preexistente de las cosas mismas, que sea independiente de la intervención de nuestra sensibilidad. A diferencia de Wolff, en Baumgarten la belleza no es la "representación sensible de la perfección", sino la perfección que tiene lugar en

${ }^{27}$ U. FrAnKe, Kunst als Erkenntnis..., o.c., p.89. La distinción aquí introducida entre "belleza natural" y "belleza artística" es, obviamente, postkantiana; no está en Baumgarten. Que el fundador de la Estética no hiciera semejante distinción y ni siquiera llegara a planteársela pone de manifiesto hasta qué punto para él el vínculo entre ambas era incuestionable y, en su caso, de carácter metafísico.

${ }^{28}$ Cf. U. Franke, Kunst als Erkenntnis..., o.c., 89-90; y Dagmar Mirbach, "Einführung: Zur fragmentarischen Ganzheit von Alexander Gottlieb Baumgarten Aesthetica (1750/1758)”, en: A. G. Baumgarten, Aesthetica, o.c., p. LIII ss. 
nuestro conocimiento sensible ${ }^{29}$. Aunque Baumgarten, siguiendo la Psychologia empirica (1732) de Wolff, relacione, sin duda, la belleza con el placer (voluptas) y el apetito debido al conocimiento intuitivoconfuso que comparten en común ${ }^{30}$, no la define, sin embargo, por esa mutabilidad empírico-subjetiva de lo placentero y deseable ni por la insuficiente claridad lógico-cognitiva de las representaciones sensibles. En cuanto fenómeno es "perceptible por el gusto en sentido amplio"31 y conlleva placer, pero lo percibido como tal por esta facultad sensible de juzgar -lo fenoménico- es la perfección misma como nexo o concordancia de las representaciones "confusas". De ahí que lo subjetivo de la belleza en cuanto perfectio phaenomenon no sea otra cosa que la estructura conexa de una serie de representaciones sensibles diversas, y, por tanto, algo objetivo, sólo que se trata de una objetividad captada por la sensibilidad humana, en vez de por el entendimiento. Esta ambivalencia o implicación entre lo subjetivo y lo objetivo, en realidad, la manera como Baumgarten ha sacado del perspectivismo monadológico de Leibniz las consecuencias pertinentes para su concepción de la belleza: ésta constituye el modo de ser la perfección en y desde la perspectiva sensible del alma humana. G.F. Meier definió muy bien la belleza en clave perspectivista al decir que es "una perfección en tanto que es conocida de manera sensible o no nítida [undeutlich]" y aclarar

${ }^{29}$ Sobre este tema y, en particular, sobre la diferencia de Wolff con Baumgarten, v. S. Tedesco, L'estetica di Baumgarten, 75-77.

${ }^{30}$ Baumgarten define la belleza en el último párrafo de la Sección XV de la "Psychologia empirica" dedicada a la voluptas et taedium, justo antes de la Sección XVI, que trata de la facultas apetitiva. La voluptas (o "complacencia") "es el estado del alma que surge de intuir una perfección" (Metaphysica, \&655), la cual como tal "deleita" (Ibíd.., \&658). Por es "lo bello como tal” -continúa el \&662 de la Metaphysica- "deleita al que lo intuye".

${ }^{31}$ Metaphysica, \&662. Los phaenomena son las "cosas observables o perceptibles": "Observabilia (phaenomena) dicimus, quae per sensus possumus cognoscere (confusius)" (Metaphysica, \&425, p.115). El "gusto en sentido amplio" es la capacidad de juzgar acerca de las cosas sensibles (Iudicium sensitivum) (Metaphysica, \&\&607-608) y, en concreto, de la "perfección de los sentidos" (Meditationes, \&92), es decir, la "aptitud para percatarse de bellezas y fealdades" (G.F. MeIER, Abbildung eines Kunstrichters, Halle (Magdeburg), 1745, \&8, p.14; cf. Anfangsgründe, 2. Theil, \&467, p.405-406), y constituye, junto con la facultas fingendi, la facultad cognoscitiva inferior que acredita a la sensibilidad como analogon rationis (Cf. Anfangsgründe, 1. Theil, \&17). 
este concepto poniendo de manifiesto la diferencia entre perfección y belleza mediante una antinomia:

"Algunas verdaderas perfecciones son verdaderas fealdades y a la inversa"; y

"Algunas verdaderas imperfecciones son verdaderas bellezas y a la inversa" ${ }^{2}$.

\section{Pluralidad en orden. "Claritas extensiva", "perceptio praegnans"}

Una vez mostrado que la belleza constituye el modo de perfección del conocimiento sensible, se trata de saber en qué consiste en concreto esa perfección. Más arriba señalamos que no podía ser de índole lógicocognoscitiva, ya que las representaciones sensibles, por su carácter "confuso", son en este sentido imperfectas. En su lugar apuntamos que Baumgarten había cifrado la perfección sensible en la complejidad y plenitud de notas de un conocimiento confuso, pero no nos detuvimos a analizar lo que esto significaba. De ello nos vamos a ocupar ahora, empezando por recordar lo que implica el concepto de perfección introducido por Leibniz.

Baumgarten define así la perfección como trascendental del ente:

"Si muchas cosas [plura] tomadas a la vez conjuntamente constituyen la razón suficiente de una, concuerdan [consentiunt] entre sí. Esta concordancia misma [consensus ipse] es la perfección, y aquella cosa [unum] en la que se concuerda, es la razón determinante de la perfección (el foco de perfección)" 33

Si prestamos atención a la secuencia de los trascendentales del ente en la Ontología de Baumgarten (unum, rerum, perfectum), comprendemos que avanza de algún modo acumulativamente de la unidad a la pluralidad. La perfección es el último de los tres, porque contiene en sí los anteriores y constituye, en este aspecto, su consumación. Lo per-

${ }^{32}$ G.F. MeIER, Anfangsgründe, 1. Theil, \&26, pp.43 y 44 respectivamente.

${ }^{33}$ A.G. Baumgarten, Metaphysica, \&94, p.46. 
fecto presupone la unidad (unum) del elemento que constituye la razón determinante de la concordancia de una pluralidad, y al mismo tiempo implica un orden, determinado por la identidad de la razón coordinadora de esa pluralidad, orden sin el cual no sería posible que lo perfecto fuera trascendental ni metafísica o realmente verdadero ${ }^{34}$. La perfección, como consenso, concordancia o acuerdo de lo múltiple en unidad, no es mera unidad ni mero orden; es un orden tenso y complejo, que resulta de la existencia de un nexo (o varios) - ratio implica nexus - de una pluralidad; un nexo que puede ser simple (razón única) pero también compuesto (razones múltiples) ${ }^{35}$. Lo perfecto constituye, por tanto, aquel trascendental del ente que pone de relieve la pluralidad, ciertamente bajo un orden, pero de tal suerte que entonces el mundo más perfecto de entre todos los posibles es aquél en el que se da la máxima pluralidad concordante de sus partes y también la máxima diversidad de sus conexiones, es decir, cuenta con una "perfección máximamente compuesta"36.

A la vista de esta noción ontológica de perfección se entienden mejor las nociones con las que Baumgarten trató de caracterizar la perfección sensible, entendida como concordancia o conexión fenoménica de diversas representaciones confusas. En las Meditationes de 1735 propuso a este respecto la noción de claridad extensiva (claritas extensiva) para subrayar la cantidad y riqueza de notas o representaciones que concurren en el (re)conocimiento sensible de un objeto, y la distinguió del concepto de claridad intensiva, con el que alude a la nitidez lógico-analítica del conocimiento racional ${ }^{37}$. Y para destacar la fuerza o potencia expresiva de un conocimiento sensible extensivamente claro Baumgarten introdujo en 1739 en su Metaphysica, \&517 el concepto

${ }^{34} \mathrm{Cf}$. Metaphysica, \&73 ("Uno es aquello cuyas determinaciones son inseparables"), \&95 ("En la perfección hay orden"), \&78 ("Orden es la identidad de una coordinación de lo múltiple”), \&89 ("La verdad metafísica es el orden de lo plural en unidad" - esta definición corresponde propiamente a la "verdad trascendental" de Wolff, según ha mostrado P. Pimpinella, "Veritas aesthetica...”, o.c., p.40 ss.).

${ }^{35} \mathrm{Cf}$. Metaphysica, \&96. Sobre la noción de razón (ratio) como fundamento de un nexo v. Ibid., \&14. De ahí que una conexión (connexum) sea de por sí racional (Ibid., \&19).

${ }^{36}$ Ibid., \&436.

${ }^{37}$ Cf. A. G. Baumgarten, Meditationes, \&16; Metaphysica, \&531; G. F. MEIER, Anfangsgründe, 1.Theil, \&33. 
de percepción pregnante, y añadió, reiterando lo dicho ya en Meditationes, \&19, que las representaciones singulares (o "ideas"), que dan a conocer lo individual como tal, son las más pregnantes y, por tanto, las más bellas.

Con esas dos nociones Baumgarten trataba, pues, de precisar el criterio estético de lo bello como perfección sensible, y a la vez insistía en que sólo el conocimiento o representación de la belleza nos acerca a esa pluralidad infinita de determinaciones de lo individual así como a la pluralidad ordenada de individuos que componen el mundo. El arte sólo podrá crear belleza si trata de imitar esta pluralidad armónica de lo real descubriendo y representando conexiones múltiples y nuevas de las cosas. La creación artística es ya de por sí una operación cognoscitiva compleja, en la que debe darse una concordancia múltiple de estos tres elementos: la belleza de los pensamientos, la de su orden y la de su expresión; la belleza artística es por ello siempre "compuesta" 38 . La perfección de este proceso de composición y de la obra resultante viene determinada en cualquier caso por la construcción de esos nexos inéditos entre representaciones sensibles diversas a los que dan lugar lo que Baumgarten, por extensión de la Lógica, denomina "argumentos" estéticos, en los cuales reside la base operativa de la racionalidad del arte. Pues un argumento es aquella representación o "conocimiento que contiene el fundamento [o razón determinante] de otro conocimiento" $39, \mathrm{y}$, por tanto, genera en torno a sí una conexión de representaciones diversas. La Estética, como arte del pensar bello o creación artística, se convierte así en una teoría de la argumentación sensible ${ }^{40}$.

\section{LA PROPUESTA: TÓPICA ESTÉTICA. UN BREVE BOSQUEJO}

La concepción de la Estética, en cuanto ciencia del perfeccionamiento artístico del conocimiento sensible, como una teoría de la

${ }^{38}$ Cf. A.G. Baumgarten, Aesthetica, \&24; cf. Kollegium, \&24. La belleza, en cuanto fenoménica, es ya perfección compuesta, pues todo fenómeno es un compuesto (cf. Metaphysica, \&234). En cuanto a los elementos que componen el "pensar bello" o creación artística v. Aesthetica, \&\&18-20.

${ }^{39}$ A.G. Baumgarten, Kollegium, \&26, p.84; cf. \&142; cf. Aesthetica, \&26.

${ }^{40} \mathrm{Tal}$ es la acertada tesis de S. Tedesco, L'estetica di Baumgarten, p.86 ss. 
construcción de "argumentos bellos" que provoquen y revelen intuitivamente conexiones fenoménicas nuevas y enriquecedoras de un mundo plural, lleva a Baumgarten a diseñar la parte teórica y general de su Aesthetica como un ars inveniendi y a desarrollarla de este modo como una revisión de la Retórica antigua a la luz (y sobre la base) de su metafísica de inspiración leibnizo-wolffiana y, particularmente, de la noción ontológica de perfección. La división tripartita proyectada de esa primera parte teórica en Heuristica, Methodologia y Semiotica reproduce fielmente - como es sabido - la estructura ciceroniana del discurso retórico (inventio, dispositio y elocutio), y muchas de las doctrinas y partes de la Retórica tradicional quedan integradas dentro de la obra en su forma antigua o resultan transformadas y revitalizadas desde otra perspectiva ${ }^{41}$. Desde la perspectiva del arte de la invención, lo peculiar de la posición de Baumgarten con respecto a la Retórica está en que él se sitúa en el marco de la crítica moderna de esta tradición y, particularmente, hace suya la exigencia de ampliación del ars inveniendi más allá del estrecho círculo del orador, pero precisamente para orientarlo (y extenderlo) hacia el campo de las bellas artes, del mismo modo que desde F. Bacon se había empezado a extender al campo de la nueva ciencia natural. ${ }^{42}$ Obviamente esta ampliación estética, que en el caso de Baumgarten va a tener muy presente la herencia retórica, tenía que plantearse al mismo tiempo -tal cual ocurriera para el caso de la ciencia moderna- como una modificación radical de los viejos

${ }^{41}$ La transformación histórica de la Retórica en la Estética durante el siglo XVIII ha sido ampliamente estudiada (véase nuestra nota 4). En el caso de Baumgarten fue decisivo el artículo de Marie Luise LinN, "A. G. Baumgartens $<<$ Aesthetica>> und die antike Rhetorik" [1967], en: Helmut Schanze (Hg.), Rhetorik. Beiträge zu ihrer Geschichte in Deutschland vom 16.-18.Jahrhundert, Frankfurt/M, 1974,pp.105-125. La estructura del discurso retórico constituye ya el esquema poetológico del proceso creador en las Meditationes de 1735.

${ }^{42}$ Como es conocido, fue P. Ramus (Dialecticae Institutiones, 1543) el primero en sustraer el ars inveniendi de la jurisdicción ciceroniana de la Retórica para trasladarlo a la Dialéctica y convertirlo así en una lógica natural aplicable a todos los ámbitos intelectuales. Baumgarten se hace eco de este giro histórico al citar a P. Ramus en Aesthetica, \&133 y al reconocer una "Tópica lógico-dialéctica" que se utilizó en los más diversos campos (\&131). Una breve panorámica sobre el plan moderno de un ars inveniendi puede encontrarse en Leonel RibeIRo Dos SANTOS, Ideia de uma heurística transcendental. Ensaios de meta-epistemologia kantiana, Lisboa, 2012, cap.2, pp.59-67. 
presupuestos teóricos y de las correspondientes reglas de construcción de discursos, para poner en su lugar las convicciones filosóficas y las demandas metodológicas de la nueva ratio moderna. El parágrafo con el que se abre el capítulo correspondiente de la "Heurística" en el Kollegium über Ästhetik deja clara la concepción que Baumgarten tiene de su Estética filosófica como arte de la invención, así como su autoconciencia de hallarse en el horizonte de la renovación de este arte por parte de los modernos.

"Vamos a hablar primero de las invenciones bellas [die schönen Erfindungen]. Por invenciones entendían los antiguos el [arte de] traer de nuevo a la memoria ideas a menudo ya establecidas. Nuestra invención va mucho más allá. Por ella entendemos la representación de una cosa por primera vez de tal modo que caiga bajo los sentidos y conmueva [in die Sinne fällt und rührt]. Ella contiene las reglas para pensar de manera bella y conmovedora cosas de las cuales hasta ahora no se ha pensado todavía así. La invención pertenece a la Estética, pues la belleza del conocimiento es su fin" ${ }^{\prime 3}$.

La clara reorientación y definición estética del ars inveniendi que pone de manifiesto este texto, conducirá a Baumgarten a emprender una doble tarea:

1) Una crítica radical de aquella parte de la Retórica encargada de la invención: la Tópica, como arte de formular argumentos. Forma parte nuclear de esa crítica la denuncia de que no constituye un auténtico arte inventivo, sino más bien un proceder mnemotécnico ${ }^{44}$, y desde luego no sirve en absoluto para la creación artística.

${ }^{43}$ A. G. Baumgarten, Kollegium, \&14, p.81.

${ }^{44}$ Sobre el carácter meramente mnemotécnico de la Tópica lógico-retórica v. Aesthetica, \&130. Esta denuncia de Baumgarten tiene a su base la decadencia y progresiva conversión histórica de la inventio tópica en mero arte de la memoria en el marco del paradigma humanístico-barroco de la "Polihistoria" (v. L. BORNSCHEUER, "Die Aufklärung der Topik...", o.c., p.57 ss.). La crítica de esa Tópica memorística, sin función inventiva, y la necesidad de una nueva Tópica es una preocupación intelectual en Alemania de filósofos (Thomasius, por ejemplo) y poetas. Salvatore TEDesco, Breitinger e l'estetica dell'Illuminismo tedesco, Palermo, 1997, pp.65 ss., ha mostrado la centralidad de este tema en la nueva "Poética crítica" de los suizos Bodmer y sobre todo Breitinger, coetáneos de Baumgarten. En los estudios sobre 
2) Y la propuesta alternativa de una nueva Tópica específicamente estética, sobre la que se vertebra todo el capítulo de la "Heuristica" - el único redactado, aunque inconcluso de la Aesthetica -, y en la que Baumgarten trabajó convencido de que constituía su aportación más original y valiosa a la nueva disciplina filosófica fundada por él.

Antes de pasar al breve examen de ambos puntos, es preciso aclarar por qué la Estética de Baumgarten no erradica del todo la idea de una Tópica inventiva, sino que se presenta como Tópica alternativa, como Tópica específicamente moderna para la creación artística. Es innegable que descarta por completo la Tópica tradicional como arte de invención de lo bello. Sin embargo, no por ello renuncia a la idea de un arte que suministre criterios y reglas para la creación artística, en vez de dejar la producción de las obras bellas a la entera libertad imaginativa del genio, como ocurrirá a partir del Sturm und Drang y de Kant. Una muestra de esa concepción es el hecho de que Baumgarten tienda a fijar en fórmulas mnemotécnicas, concretamente en versos (o a usar versos célebres de autores clásicos), la mayoría de las reglas inventivas que propone. Es la concepción de la Estética filosófica aún como un arte que puede dirigir racionalmente la invención e incluso corregirla - conforme a la idea wolffiana del saber filosófico como emendatio -, la que hace de Baumgarten no un destructor de la Tópica en su función inventiva, sino su refundador moderno. Naturalmente, será este lado "científico-técnico" de la Aesthetica el que no tenga continuidad en la filosofía del arte posterior a Baumgarten, a diferencia del lado "psicológico-subjetivo" que - como veremos - él puso también de relieve, si

Baumgarten la relación de su Estética con la Tópica tradicional apenas se ha investigado o se ha abordado de manera marginal o poco relevante (así M.L. LinN, "A. G. Baumgartens «Aesthetica»..", o.c., p.121 ss., y Ursula Franke, "Mit der Metaphysik im Rücken...", o.c., p.232 ss.), sin poner de manifiesto su alcance histórico y su centralidad en el proyecto estético del profesor de Frankfurt am Oder. Sólo la investigación italiana ha destacado con acierto este tema (v. Pietro PIMPINELLA, "Hermeneutik und Ästhetik bei A.G. Baumgarten", en: Manfred BEETZ/Giuseppe Cacciatore (Hg.), Die Hermeneutik im Zeitalter der Aufklärung, Weimar/Wien, 2000, pp.265-283, espec. 279 ss.; y sobre todo S. TEDESCO, L'estetica di Baumgarten, 1077 ss.). 
bien lo consideró como un aspecto más del arte estético, como la otra perspectiva de la Tópica estética.

\section{Crítica de la Tópica tradicional}

En la Aesthetica la sección X (\&\&130-141) del capítulo de la "Heuristica", justamente después de exponer el primero y fundamental de los nuevos criterios estéticos (ubertas), está dedicada a presentar lo que ha sido históricamente la Tópica, a incluir dentro de ella, como ampliación reciente, la nueva Ontología de Baumgarten, basada en Wolff, a declararla inútil para la invención artística y a proponer finalmente una Tópica estética alternativa. En lo concerniente a su posición crítica con respecto a la Tópica tradicional, podemos encontrarla sintetizada en la siguiente aclaración de su Kollegium über Ästhetik:

"En lo bello cesa [fällt...weg] la Tópica general y ahí presta su servicio la particular" 45 .

Baumgarten rechaza el núcleo central de la Tópica tradicional, a saber, la "Tópica general”, que contenía los loci universales usados para construir argumentos sobre todos los temas y asuntos; sólo reconoce la utilidad de algunos de sus modelos (por ejemplo, el retórico de Quintiliano, o el lógico-escolástico del genus, species, individuum...) como mero ejercicio preliminar del pensamiento y la memoria ${ }^{46}$, o su validez en todo caso para el conocimiento intelectual. En este aspecto cabe destacar su propuesta de convertir los títulos y conceptos de su Ontología en la nueva Tópica general ${ }^{47}$. En cualquier caso la inutilidad de todo tipo de Tópica general para la invención bella reside en su incapacidad de proporcionar ese conocimiento de lo individual que caracteriza al arte bello. Los loci universales "nunca se ajustarán bien a las cosas. Son comparables a vestidos hechos para un cuerpo humano estándar". Por

\footnotetext{
${ }^{45}$ Kollegium, \&138, p.140.

${ }^{46}$ Cf. Ibíd., \&\&133, 135; Aesthetica,\&137. El arte de R. Lulio es desautorizado por completo y tampoco se valora bien la tabla de las 10 categorías aristotélicas.

${ }^{47} \mathrm{Cf}$. Aesthetica, \&\&138 y 140 respectivamente.
} 
ello su empleo para la invención sólo puede proporcionar "nimiedades superfluas y ridículas" y rodeos vacuos ${ }^{48}$.

En este acercamiento a lo específico y distintivo de las cosas parece residir en principio la ventaja de la(s) Tópica(s) particular(es), que se refiere(n) a los lugares específicos de ciertos temas o áreas temáticas fijados usualmente por las ciencias particulares como fuentes de conocimiento. Sin descartar su utilidad inventiva en general, pero sin dejar de prevenir a la vez de los peligros de afectación y vacuidad cognoscitiva en los que puedan incurrir estos topoi relativos a la differentia specifica ${ }^{49}$, Baumgarten considera que sólo los "predicados propios" de un individuo, que definen su differentia numerica singular, sirven realmente para la invención bella ${ }^{50}$. Con el fin de captar y llegar al conocimiento sensible de esas notas individuantes propone una "Tópica estética" como genuina tópica particular de la invención artística, en la que sus loci particulares constituyan auténticas sedes de la argumentación bella, esto es, hilos conductores en la búsqueda de representaciones sensibles que sean rationes determinantes de conexiones intuitivas novedosas y complejas ${ }^{51}$.

\section{Los criterios de perfección cognoscitiva como topoi de invención artística}

El sentido y finalidad de la Tópica estética propuesta por Baumgarten se desprende claramente del fragmento antes citado de su Kollegium über Ästhetik, \&14. El objetivo es suministrar mediante ella reglas que sirvan para crear obras bellas y conmovedoras. Baumgarten vin-

${ }^{48}$ Kollegium, \&\&138 y 135 respectivamente. Cf. Aesthetica, \&138.

${ }^{49}$ Cf. Aesthetica, \&139; Kollegium, \&135. La división de Baumgarten entre "Tópica general" y "particular" se basa en la tipología de la differentia de Tomás de Aquino: diversitas (los géneros), differentia specifica (las especies), differentia numerica (las diferencias entre individuos de una especie) y differentia accidentalis. Mientras que la Tópica general concierne a las nociones argumentativas sobre los géneros, las Tópicas particulares se refieren a las determinaciones propias de las especies y de los individuos.

${ }^{50}$ Aesthetica, \&135; Kollegium, \&135.

${ }^{51}$ Baumgarten usa las expresiones Topica aesthetica y topoi aesthetici para referirse a su propuesta en Aesthetica, \&\&131, 139 y 140. 
cula aquí estrechamente la belleza artística con el movere retórico y, por tanto, con la capacidad de emocionar, de provocar los afectos del individuo ${ }^{52}$. Un arte tópico con estos propósitos ha de revisar y reducir por ello la relación tradicional de argumentos retóricos (probantia, illustrantia, moventia) a dos tipos principales: los amplificadores (argumenta amplificantia, locupletantia), orientados al aumento de notas y conexiones de las cosas, esto es, a la belleza; y los que son capaces de mover los apetitos y pasiones humanas (argumenta moventia) ${ }^{53}$.

Es preciso destacar, por otra parte, que, si bien Baumgarten considera que la creación de una obra bella y emotiva es una tarea de invención compleja en la que han de coordinarse - como se indicó más arriba- las ideas o representaciones sensibles, el orden entre ellas y su expresión adecuada (pensamiento, método y signo), pone el peso de la invención de argumentos en la creación de ideas nuevas y bellas, de ocurrencias intuitivas originales y eficaces, hasta el punto de que su Heurística en sentido estricto y con ella la Tópica estética se reducen principalmente a suministrar los criterios y reglas de esta actividad interna de la sensibilidad humana del artista, en la que la facultas fingendi ocupa un papel central. Hay en ello, sin duda, un intencionado alejamiento polémico de la reducción creciente de la inventio retórica moderna a doctrina del adorno expresivo y del juego estilístico. Los tratados de Retórica denuncia Baumgarten - "se detienen en su mayor parte en la expresión e incluso en algún tipo especial de designación", pasando por alto, sin embargo, "la belleza del orden y de los pensamientos" 54 . Frente a esta concentración decadente de la Retórica en la dictio y la elocutio Baumgarten plantea la prioridad de la cogitatio, a sabiendas de que si no hay buenas ideas difícilmente puede haber una buena obra de arte. En este aspecto se ha señalado, no obstante, que el fundador de la Estética

${ }^{52}$ M.L. LinN, o.c., pp.119-120 subraya con razón que Baumgarten propone una "Estética del efecto" poético que busca mediante el arte impresionar antes que educar a la manera ilustrada, sin abogar aún por el irracionalismo pre-romántico. Al respecto véase también S. Tedesco, L'estetica di Baumgarten, 80, 151 ss., quien pone en relación este propósito conmovedor con el sexto y último de los criterios estéticos, la vita cognitionis, que representa así la culminación o el "clímax" de una obra bella .

${ }^{53}$ Cf. Kollegium, \&26, p.85.

${ }^{54}$ Cf. Ibíd., \&20, p.82. 
ha preservado en buena medida los genera dicendi retóricos, sólo que reformulados como rationes cogitandi o estilos de pensar ${ }^{55}$.

Teniendo en cuenta, pues, aquel propósito estético-efectista y esta prioridad concedida a la invención de ideas bellas, comprendemos ahora que el catálogo de topoi aesthetici propuestos por Baumgarten siga un orden de concordancia progresiva o perfeccionamiento del conocimiento estético hasta alcanzar el efecto emotivo final, y que además esas categorías estéticas se presenten sobre todo como criterios de invención de argumentos y figuras de pensamiento bello (figurae sententiae). ¿Pero cuáles son esos topoi?

En el \&139 de la Aesthetica Baumgarten menciona los 6 criterios o categorías de perfección del conocimiento en general contemplados en su Metaphysica, \&669 (cf.\&\&515 y 531), y que, referidos al conocimiento sensible en particular, había presentado en el \&22 como categorías estéticas o criterios en los que venía a concretarse aquella claritas extensiva en la que él inicialmente había cifrado la perfección sensible en sus Meditationes de 1735. Son éstos: ubertas (riqueza, abundancia...), magnitudo (grandeza, nobleza, sublimidad...), veritas (se reduce estéticamente a verosimilitudo), claritas o lux (claridad en el sentido de vivacidad), certitudo (se reduce estéticamente a persuasio) y vita (vitalidad o capacidad de dar vida a emociones y afectos). Estas 6 categorías estéticas definen la estructura y el contenido de toda la "Heurística" en la Aesthetica, puesto que como criterios de belleza Baumgarten las considera a la vez base tipológica de los argumentos y de las figuras ${ }^{56}$. La importancia que ellos tienen en el proyecto de Baumgarten, no sólo como novedad sino también como especificación objetivo-fenoménica de la ratio estética, contrasta, sin embargo, con el olvido al que los condenó la posteridad.

Mejor suerte parece haber tenido la propuesta paralela de una Tópica psicológica, que Baumgarten incluye también en los \& 139-140 de su Aesthetica, y que consiste en tomar como hilos conductores de la invención las propias facultades inferiores de conocer (sentidos, imaginación, memoria, ingenio, agudeza, gusto, facultad de ficción, facultad de expresión y facultad de apetecer) estudiadas en su "Psicología

\footnotetext{
${ }^{55}$ Cf. M.L. Linn, o.c., 109-111, 124; S. Tedesco, L'estetica di Baumgarten, 81.

${ }^{56} \mathrm{Cf}$. Kollegium, \&\&26,142. También la parte inventiva de los Anfangsgründe de Meier está estructurada conforme a estos 6 criterios estéticos.
} 
empírica", como fuentes del pensamiento poético. Estamos, en realidad, ante una misma propuesta de Tópica estética, si bien desde dos perspectivas distintas: la objetivo-metafísica de las perfecciones sensibles como tales y la subjetivo-psicológica del analogon rationis que las representa y crea. La diferencia está en que aquélla forma parte de la disciplina aesthetica de la creación, mientras que esta última hace valer la natura o dotación innata del sujeto creador, la cual en cualquier caso Baumgarten considera, junto con el impetus o entusiasmo, condición prioritaria, base indispensable de la invención bella. Será este lado subjetivo, conducente a la teoría pre-romántica del genio, el que desarrollará la posteridad, desprendiéndose del conjunto de reglas racionales de argumentación estética que aquella Tópica objetiva de la perfección sensible llevaba consigo. Pero con ello también desaparecía aquella idea de un "análogo de la razón", en la que Baumgarten cifraba la acreditación de la sensibilidad humana como fundamento subjetivo de la racionalidad estética. 